\title{
A mapping review of sacrococcygeal pilonidal sinus disease
}

\author{
M. Kumar' ·W. H. Clay ${ }^{2}$ M. J. Lee 2,3(1) S. R. Brown² D. Hind ${ }^{4}$
}

Received: 4 August 2020 / Accepted: 25 February 2021 / Published online: 16 March 2021

(c) The Author(s) 2021

\begin{abstract}
Background Pilonidal sinus is a hole in the natal cleft which may cause severe pain and become infected. The evidence base for management of pilonidal sinus is said to be poor quality, poorly focused and rapidly proliferating. We undertook a systematic mapping review to provide a broad overview of the field and support the identification of research priorities.

Methods We searched MEDLINE, CINAHL, and EMBASE from inception to 22nd Nov 2020 for primary research studies focused on the management of pilonidal sinus. We extracted data on study design and categorised studies under five major headings ('non-surgical treatment', 'surgical treatment', 'aftercare' and 'other'), producing frequency counts for different study designs. Gaps in research were identified from published systematic reviews and tabulated.

Results We identified 983 eligible studies, of which 36 were systematic reviews and/or meta-analyses; 121 were randomised controlled trials), and 826 observational studies of various design. The majority of studies evaluated surgical techniques $(n=665)$, or adjuvant medical interventions $(n=98)$. The literature on wound care has developed most recently, and the evidence base includes $30 \%$ randomised controlled trials. Gaps analysis highlighted comparison of surgical techniques including flaps, laser depilation, and wound care interventions as potential areas for randomised controlled trials.

Conclusions This mapping review summarises eight decades of research on the management of pilonidal sinus. Further research is needed to identify front-running interventions, understand variation in practice and patient values, and to prioritise future research.
\end{abstract}

Keywords Pilonidal sinus $\cdot$ Mapping review $\cdot$ Systematic map $\cdot$ Surgery $\cdot$ Wound care

\section{Introduction}

Pilonidal sinus disease predominantly refers to the condition of in-growing hair in the natal cleft. It typically affects younger, and economically active, men, and can cause pain and local sepsis [1]. It is often recurrent and challenging to treat [2]. Even where healing of the primary cause is achieved, there can be longer-term challenges related to wound healing [3]. The absence of a front-running

M. J. Lee

M.j.lee@sheffield.ac.uk

1 The Medical School, University of Sheffield, Sheffield, UK

2 Academic Directorate of General Surgery, Sheffield Teaching Hospitals NHS Foundation Trust, Sheffield, UK

3 Department of Oncology and Metabolism, FU32, F Floor, Medical School, University of Sheffield, Sheffield S10 2RX, UK

4 Clinical Trials Research Unit, School of Health and Related Research, University of Sheffield, Sheffield, UK intervention reliably associated with long-term healing, and concerns about research deficits [4] have led to widespread variation in practice [5] and concern that practice is not evidence based [6]. The rapidly proliferating scientific literature on pilonidal sinus is said to be poor and to comprise principally of single-centre case series and non-randomised comparative studies, leading to calls for more focused, better-quality research [4].

Mapping reviews, or systematic maps, use systematic searches on a broad topic, to make large bodies of literature "accessible, digestible and useable" [7]. Rather than addressing the findings of studies, they assess activity in an area of research. This allows researchers to identify which aspects of a problem have publications associated with them [8]. Where activity cannot be identified related to an aspect of a disease or condition, it might be considered a gap. Mapping reviews are an increasingly used method of identifying research gaps and priorities in a broad field $[8,9]$. In surgery, mapping reviews have previously summarised the literature, and clinical uncertainty, in broad fields such as 
oral and maxillofacial surgery [10] and tele-orthopaedics [11]. In this paper, we report a mapping review of sacrococcygeal pilonidal sinus.

The aim of the study was to categorise the literature using accessible graphical formats to highlight the most robust current evidence. This will allow healthcare professionals to understand what areas of the disease are well or less well researched, improving decision-making and guiding future research.

\section{Materials and methods}

\section{Search strategy}

Searches of the MEDLINE, EMBASE, and CINAHL databases were performed, from inception of database to 22nd Nov 2020 for citations indexed with the MeSH term "pilonidal sinus", without date or language restrictions.

\section{Study selection}

Eligible citations were systematic reviews, controlled trials, cohort studies, case-control studies; cross-sectional studies; ecological studies; case series and case reports. Citations for which no abstract was available, case reports based on a single patient, non-systematic review articles, comments and letters were all ineligible for inclusion. Articles for which the primary focus was not sacrococcygeal pilonidal sinus were also excluded from this mapping review.

\section{Data extraction}

From the study abstracts and full-text articles where necessary (i.e., where abstract was not available), we extracted the date of publication, type of study, intervention, comparator (if any), outcome measures, MeSH terms identified as the focus of the article, and the number of patients.

\section{Categorisation}

The study group agreed on a clinical categorisation system which included four major headings (Table 1): non-surgical treatment, surgical treatment, aftercare, and other. 'Non-surgical treatment' was subcategorised into hair removal and other. 'Surgery' was subcategorised into surgical techniques and chemicals or drugs. 'Surgical techniques' was further broken down with the assistance of two clinicians into flaps; off-midline closure; midline closure; excision only; minimal excision only; marsupialisation; drainage; endoscopic; laser; radiofrequency and other. 'Chemicals and drugs' was further broken down into phenol; fibrin; methylene blue; platelet-rich plasma; pre/intraoperative antibiotics and other.
'Aftercare' was subcategorised into wound care and nonwound care. The subcategory of 'wound care' was further broken down into negative pressure wound therapy; foam dressing; alginate dressing; hydrocolloid dressing; hydrofibre dressing; hydrogel dressing; gauze; platelet-rich plasma; postoperative antibiotics and other.

The category of 'other' was further subcategorised into aetiology and complications; epidemiology; health utility and other. The subcategory aetiology and complications was further broken down into patient risk factors; postoperative complications; family history; hair analysis; microbiology; cellular/chemical factors; coexisting conditions, and anatomical factors. Since one study may investigate more than one intervention, some of the studies overlap between the categories and subcategories. After the studies had been categorised and subcategorised, a master table was created, with frequency counts (numbers of studies) for clinical categories, and subcategories, as well as for each type of study design.

\section{Gaps analysis}

We accessed the full texts of systematic reviews identified through the searches, and tabulated explicit recommendations, for further research. In areas where there were not yet systematic reviews, we noted whether there was more than one, one, or no randomised controlled trials (RCTs) yet.

\section{Results}

Searches identified 3202 citations indexed with the MeSH heading 'pilonidal sinus' and in Embase, CINAHL, and Central. At screening, 2156 were excluded. Of the remaining 983 studies, published between 1945 and 202036 were systematic reviews and/or meta-analyses; 121 were RCTs, and 826 observational studies of various design.

\section{Categorisation}

The number of studies included in each category, and the relevant study design are presented in Fig. 1 and in the web-only Appendix. Figure 2 demonstrates the coverage of domains by year of publication, and Fig. 3 demonstrates the study designs reported each year. These demonstrate that the majority of the literature addresses surgical techniques, and is dominated by cohort studies.

\section{Non-surgical treatment}

In the category of non-surgical treatment, there were 4 systematic reviews, 2 RCTs and 29 observational studies of various design. Topics included: hair removal (4 systematic 
Table 1 Taxonomy of studies

\begin{tabular}{|c|c|c|}
\hline Major heading & Minor heading & Sub-group \\
\hline \multirow[t]{2}{*}{ Non-surgical treatment } & Hair removal & - \\
\hline & Other & - \\
\hline \multirow[t]{17}{*}{ Surgical treatment } & Surgical techniques & Flaps \\
\hline & & Off midline closure \\
\hline & & Midline closure \\
\hline & & Excision only \\
\hline & & Minimal excision \\
\hline & & Marsupialisation \\
\hline & & drainage \\
\hline & & endoscopic treatment \\
\hline & & Laser treatment \\
\hline & & radiofrequency treatment \\
\hline & & Other \\
\hline & Chemicals and drugs & Phenol \\
\hline & & Fibrin \\
\hline & & Methylene blue \\
\hline & & Platelet rich plasma \\
\hline & & Pre/intraoperative antibiotics \\
\hline & & Other \\
\hline \multirow[t]{10}{*}{ Aftercare } & Wound-care & Negative pressure wound therapy \\
\hline & & Foam dressing \\
\hline & & Alginate dressing \\
\hline & & Hydrocolloid dressing \\
\hline & & Hydrofibre dressing \\
\hline & & Hydrogel dressing \\
\hline & & Gauze \\
\hline & & Platelet rich plasma \\
\hline & & Post-operative antibiotics \\
\hline & Other & - \\
\hline \multirow[t]{12}{*}{ Other } & Aetiology and complications & Patient risk factors \\
\hline & & Post-operative complications \\
\hline & & Family history \\
\hline & & Hair analysis \\
\hline & & Microbiology \\
\hline & & Cellular/chemical factors \\
\hline & & Coexisting conditions \\
\hline & & Anatomical factors \\
\hline & Epidemiology & - \\
\hline & Qualitative & - \\
\hline & Health utility & - \\
\hline & Other & - \\
\hline
\end{tabular}

reviews; 1 RCT and 28 observational studies); conservative treatment (1 RCT and 3 observational studies).

\section{Surgery}

In the category of surgery, there were 26 systematic reviews/ meta-analyses, 80 RCTs and 622 observational studies of various designs.
Under the subheading surgical techniques, the topics included: flap (14 systematic reviews/meta-analyses; 38 RCTs and 222 observational studies); midline closure (10 systematic reviews/meta-analyses; 30 RCTs and 163 observational studies); off-midline closure (12 systematic reviews/ meta-analyses; 21 RCTs and 116 observational studies); excision only (9 systematic reviews/meta-analyses; 28 RCTs and 121 observational studies); minimal excision only (6 


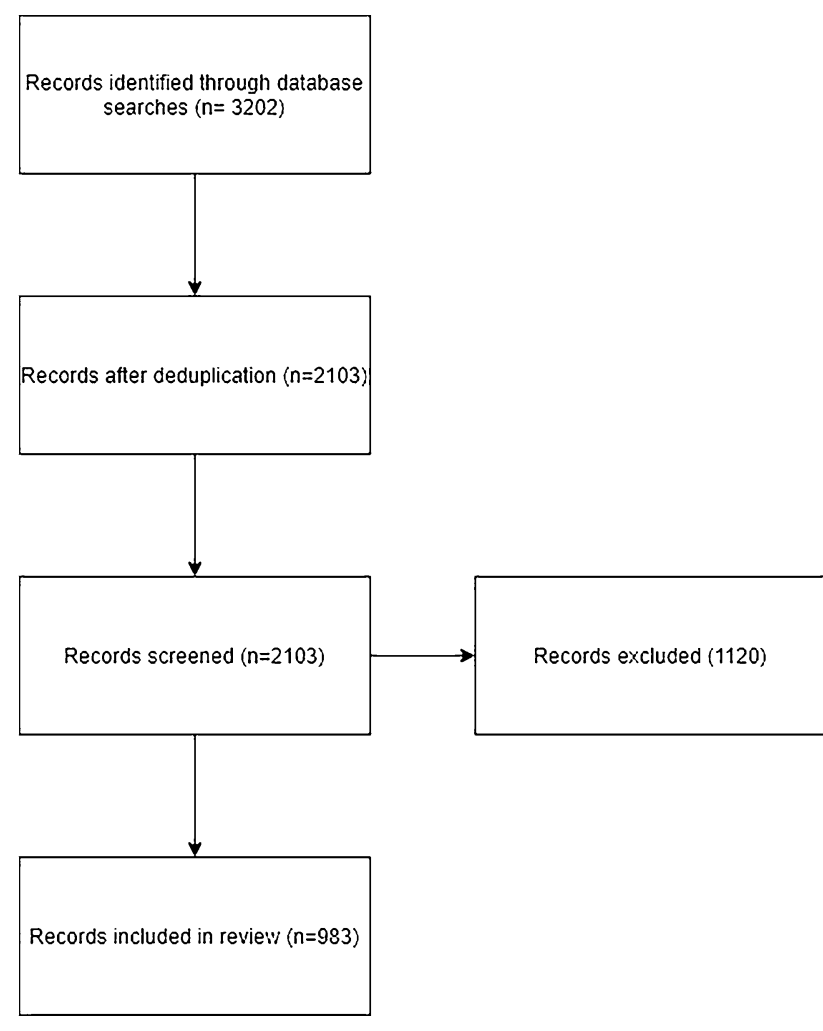

Fig. 1 PRISMA flow chart systematic reviews/meta-analyses; 3 RCTs and 61 observational studies); marsupialisation (2 systematic reviews/metaanalyses; 6 RCTs and 31 observational studies); endoscopic (4 systematic reviews/meta-analyses; 1 RCTs and 47 observational studies); drainage (1 systematic reviews/meta-analyses and 8 RCTs); laser (2 systematic reviews/meta-analyses and 23 observational studies); radiofrequency (1 systematic reviews/meta-analyses; 3 RCTs and 3 observational studies); other (2 systematic review/meta-analyses; 4 RCTs and 32 observational studies) (Fig. 2).

Under the subheading chemical and drugs, the topics included: phenol (4 systematic reviews/meta-analyses; 3 RCTs and 31 observational studies); fibrin glue (4 systematic reviews/meta-analyses; 3 RCTs and 11 observational studies); pre/intraoperative antibiotics (2 systematic reviews/ meta-analyses; 16 RCTs and 5 observational studies); methylene blue ( 7 observational studies); platelet-rich plasma ( 2 RCTs and 2 observational study); other (1 RCT and 6 observational studies) (Fig. 3).

\section{Aftercare}

In the category of aftercare, there were: 3 systematic reviews; 20 RCTs and 51 observational studies of various designs.
Fig. 2 Major and minor domains identified by year published

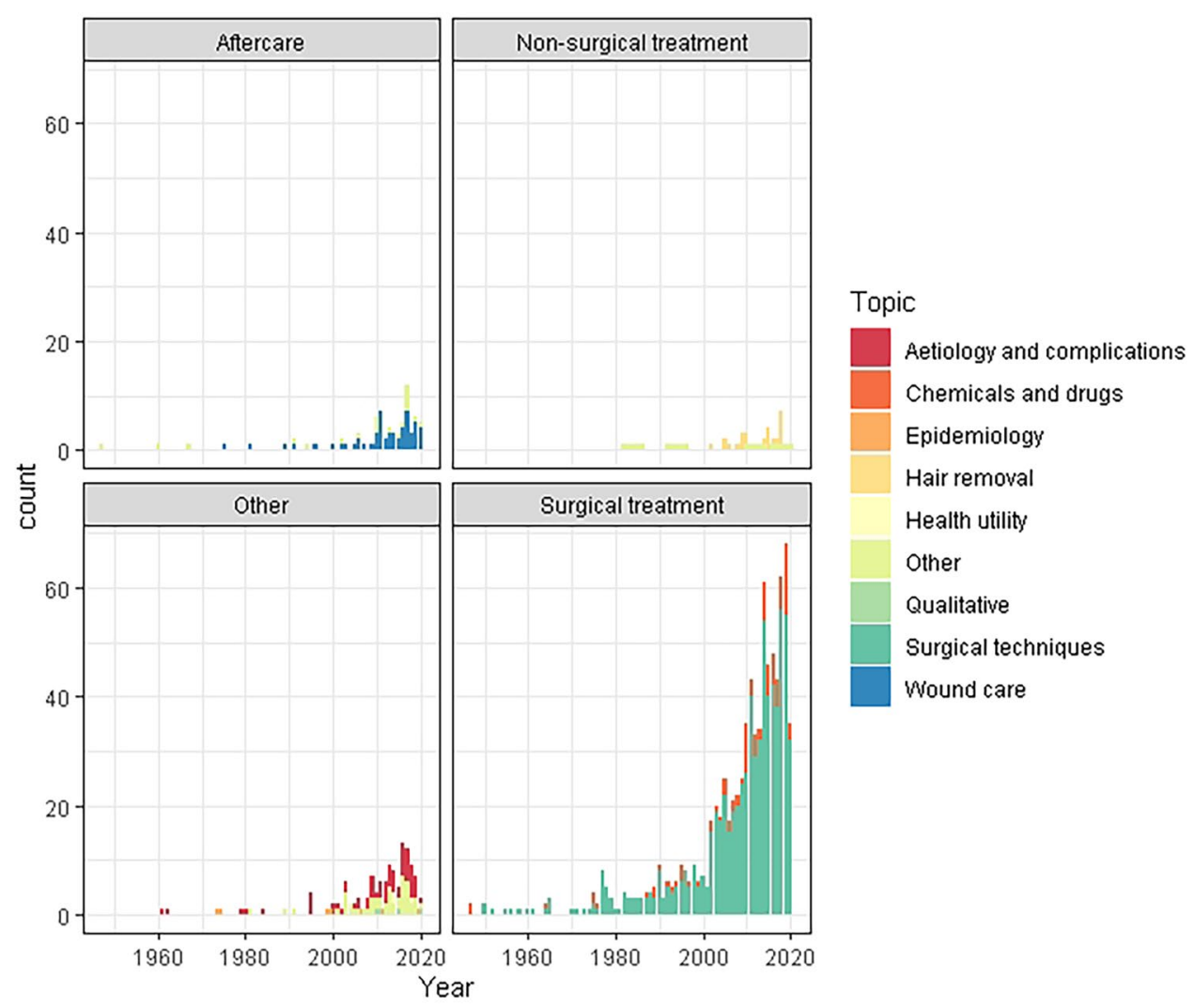


Fig. 3 Study design used by year published

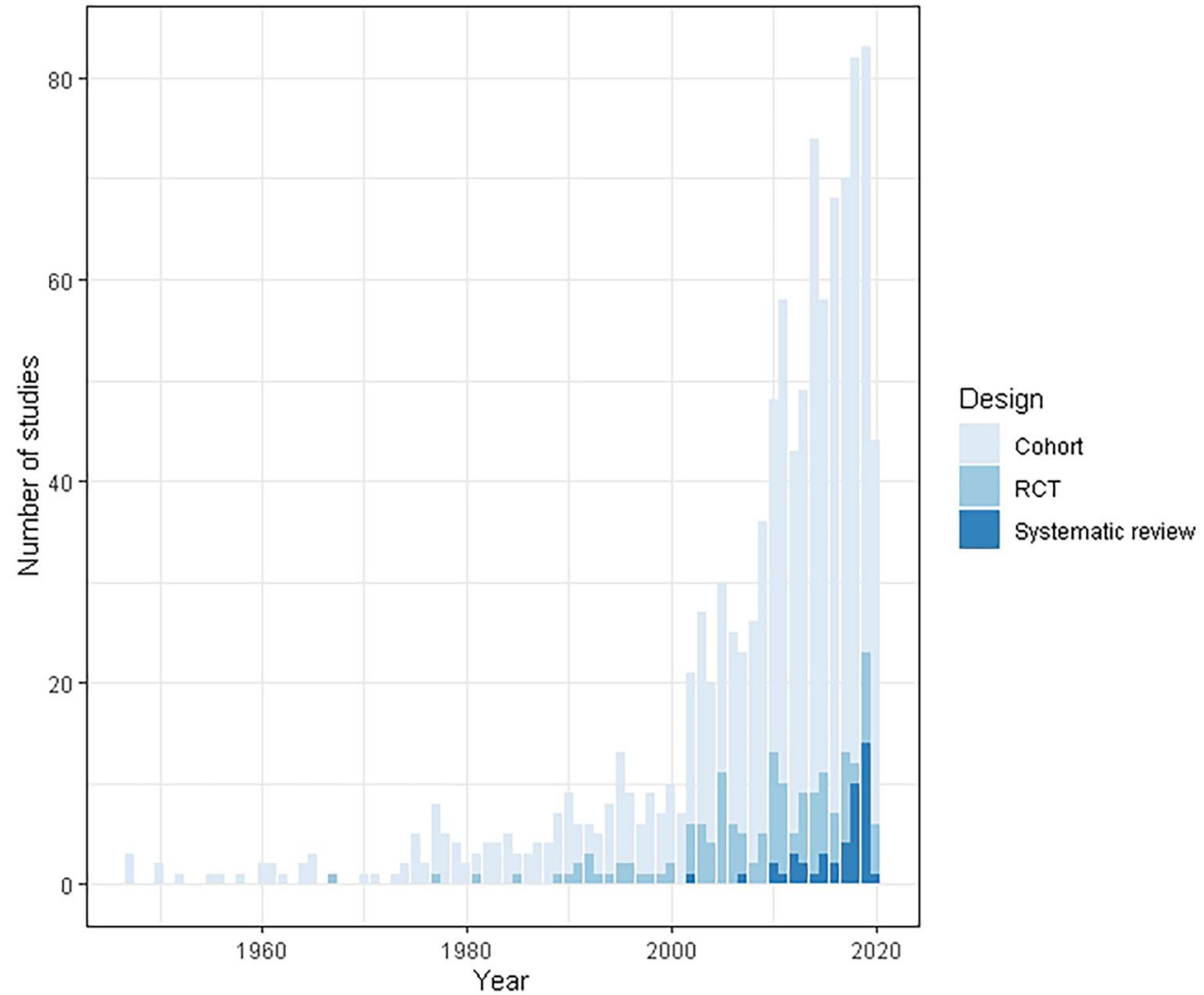

Under the subheading of wound care topics included: negative pressure wound therapy ( 1 systematic review; 2 RCTs and 15 observational studies); foam (1 systematic review; 2 RCTs and 3 observational studies); alginate (1 systematic review; 3 RCTs and 2 observational studies); hydrocolloid (2 RCTs and 2 observational studies); hydrogel (1 RCT and 1 observational study); hydrofibre (1 observational study); gauze (2 RCTs and 6 observational study); collagenase dressing (1 RCT and 1 observational study); silver dressing ( 2 observational studies); hydrophilic dressing ( 1 observational study); platelet-rich plasma therapy (1 systematic review; 1 RCT and 2 observational studies); postoperative antibiotics (1 systematic review; 3 RCTs and 8 observational studies); other (1 systematic review; 9 RCT and 17 observational studies). Under the subheading nonwound care, there were 2 RCTs.

\section{Other}

In the category of other, there was: 1 systematic review; 10 RCTs and 119 observational studies of various designs.

The subgroup aetiology and complications included: patient risk factors $(n=28)$; risk factors for postoperative complications $(n=17)$; family history $(n=3)$; hair analysis $(n=5)$; microbiology $(n=4)$; cellular/chemical factors $(n=11)$; coexisting conditions $(n=5)$; anatomical factors $(n=6)$. The epidemiology descriptor was assigned to 8 studies, and quality of life descriptor was used for four studies. All studies in this group were cohort studies. There were four qualitative research studies.

\section{Gaps analysis}

Most systematic reviews recommended RCTs of non-specific design with longer follow-up and improved methods, especially in approaches to aftercare (Table 2). For surgical techniques, there is a need for trials comparing different types of flaps [12,13], and comparing midline vs off-centre closure $[14,15]$. There is also a need for trials comparing minimally invasive procedures with standard care [16-18]. Reviews noted a lack of trials addressing emergency treatment of pilonidal sinus, the role of lateral excision only, cryosurgery, or use of setons. There were gaps in data addressing the preservation or obliteration of natal cleft, and in the use of photodynamic therapy. In the use of chemicals and drugs, there is a need for the economic evaluation of gentamicin collagen sponges and implants [19]. Systematic reviews also called for RCTs addressing the use of methylene blue. There were also gaps in data exploring laser depilation to prevent recurrence $[20,21]$. There was a clear need for further data exploring the roles of wound care adjuncts in the aftercare setting [22, 23]. 
Table 2 Gaps analysis

\begin{tabular}{|c|c|}
\hline Field & Recommendation \\
\hline Surgery & $\begin{array}{l}\text { Systematic reviews call for: trials comparing Limberg versus Karydakis flaps [12, 13]; trials of primary tension-free mid- } \\
\text { line closure in the absence of lateral pits [14]; trials of flap with off-midline repairs [15]; trials evaluating off-midline } \\
\text { closure [46]; trials of minimally invasive techniques [16]; trials of standardised endoscopic techniques versus other } \\
\text { minimally invasive or conventional procedures [17, 18]; prospective studies on-particularly minimally invasive- } \\
\text { techniques in paediatrics [47, 48]; economic studies comparing flap repair and laying open [49]; and need for core } \\
\text { outcome sets [47, 50] } \\
\text { Topic with more than one RCT possibly meriting systematic review: diathermy } \\
\text { Topic with insufficient RCTs to warrant systematic reviews: Bascoms } 1 \\
\text { Topics with no RCTS: grafts; emergency care; lateral excision only; cryosurgery; setons, preservation or obliteration of } \\
\text { natal cleft; photodynamic therapy }\end{array}$ \\
\hline Chemicals and drugs & $\begin{array}{l}\text { Systematic review calls for: economic studies on gentamicin collagen sponges and implants [19] } \\
\text { Topics with no RCTs: methylene blue }\end{array}$ \\
\hline Non-surgical & $\begin{array}{l}\text { Systematic reviews call for: trials on laser hair depilation to prevent recurrence }[20,21] \\
\text { Topic with insufficient RCTs to warrant systematic reviews: conservative treatment }\end{array}$ \\
\hline Aftercare & $\begin{array}{l}\text { Systematic reviews call for: trials of platelet-rich plasma therapy [22]; further trials on gentamicin collagen sponges [23] } \\
\text { Topics with more than one RCT, meriting systematic review: hydrocolloid; gauze } \\
\text { Topics with insufficient RCTs to warrant systematic reviews: hydrogel } \\
\text { Topics with no RCTs: hydrofibre, silver dressing; hydrophilic dressing }\end{array}$ \\
\hline
\end{tabular}

$R C T$ randomised controlled trial

\section{Discussion}

We undertook a mapping review of the published evidence on the management of pilonidal sinus. The published literature covered in this review spans eight decades. The findings show that, for most topics on which there are two or more randomised controlled trials, there is a relatively up-to-date systematic review, the exceptions being in the study of the effects of platelet-rich plasma, hydrocolloid dressings, gauze and postoperative antibiotics (Appendix).

The literature currently focuses on the management of pilonidal sinus using surgical treatments and adjuvant therapy in the form of supplementary chemicals and drugs. Only $12 \%$ of the 983 identified primary research articles were randomised trials. This suggests a reliance on cohort studies which, while appropriate for studies of natural history, risk factors, and early evaluation of novel approaches, cannot provide us with trustworthy estimates of treatment effects. In this regard, the wound care literature is more robust than other areas, with RCTs accounting for $25 / 83$ (30.1\%) of all primary research in this study.

Our aim was to provide a broad overview of the published literature rather than a more fine-grained analysis of a more specific and focused body of work, but we acknowledge several other limitations besides. The justification for drawing the gaps analysis on the recommendations of systematic reviews is that Cochrane reviews tend to concentrate on necessary methodological improvements, rather than providing explicit recommendations for further RCTs which may in fact be merited. On the other hand, readers should check trial registries for ongoing trials before acting on research recommendations from non-Cochrane reviews, which sometimes make the case for research the authors intend to undertake. While the involvement of a second reviewer is de rigueur in systematic reviews of therapeutic effectiveness [24], it is considerably more costly and only marginally more effective [25]. For this reason, we consider it defensible in an exercise intended to characterise a broad field, rather than inform policy on specific decision problems.

This mapping review confirms the absence of clear, front-running surgical interventions for pilonidal sinus [4]. In addition, the literature likely has problems relating to heterogeneity in the definition [26-31] and measurement [28, 32] of clinical outcomes. For this reason, calls to standardise endpoints within specialty areas are becoming increasingly common [30, 33, 34]. In addition to definitional harmonisation, core outcome sets can also help to reduce the selective reporting of outcomes (outcome reporting bias [35]).

A mapping review is not without its limitations. Notably, it takes a high-level approach in the assessment of the literature. This means the underlying studies have not been robustly quality assessed. As such, the recognition of 'gaps' in the literature relates to tallies of coverage rather than quantity and quality of studies. The categories selected were generated by the research team, and could be considered broad. The study classification system and allocations were reviewed by surgeons and researchers in the field, which should support their validity. The authors also noted the use of 'standard care' as a comparator. This may have changed over the decades but was not extracted here, so should be interpreted with caution. However, the broad search terms across multiple databases, and extensive numbers of citations reviewed can reassure readers that this is a fairly exhaustive list of studies in the field. 
The publication of the Idea, Development, Exploration, Assessment, Long-term Follow-up (IDEAL) Framework [36] for improving the quality of surgical research has stimulated the development of large, multicentre, prospective longitudinal cohorts designed to understand variations in practice and their effects on outcomes [37-39]. The ongoing Pilonidal sinus Treatment-Studying the Options (PiTStOp) study aims to recruit 800 people with the aim of identifying the most common combinations of excision and closure techniques used in UK practice (ISRCTN95551898) [40]. While PiTStOP will report healing, recurrence and re-intervention rates, stratified by severity of disease, a principal objective is to inform a large nominal group technique consensus exercise, currently scheduled for Jul 2021, on optimal management and research priorities. Published qualitative research already describes the lived experience of pilonidal sinus [41, 42], the frequent disconnect between provision and the expectations of service-users [43], as well as the use of poorly evidenced interventions [6]. The PiTStOp programme of research will improve our understanding of the context of pilonidal sinus management through: large-scale surveys about shared decision-making [44] and decision regret [45]; a discrete choice experiment to assess which interventions patients would rather avoid and which outcomes they most value; semi-structured interviews aimed at understanding service-user decision-making and practical coping strategies.

This study provides a useful starting point for researchers. It has collated, in one place, a summary of the knowledge of the management of pilonidal sinus disease. It demonstrates the range and nature of interventions explored, albeit at a high level, and the types of studies underpinning these. These data, plus the gaps analysis, should provide researchers with a springboard for further research in the area.

\section{Conclusions}

This systematic mapping review provides an accessible overview of eight decades of research on the management of pilonidal sinus. It confirms the presence of a range of interventions and adjuncts for the care of pilonidal sinus, many of which have not been explored in RCTs. Further research is needed to understand variation in practice and patient values, as well as to prioritise future research.

Supplementary Information The online version contains supplementary material available at https://doi.org/10.1007/s10151-021-02432-9.

Funding None.

\section{Compliance with ethical standards}

Conflict of interest None.

Ethical approval This article does not contain primary research data from patients.

Informed consent For this type of study, informed consent is not required.

Open Access This article is licensed under a Creative Commons Attribution 4.0 International License, which permits use, sharing, adaptation, distribution and reproduction in any medium or format, as long as you give appropriate credit to the original author(s) and the source, provide a link to the Creative Commons licence, and indicate if changes were made. The images or other third party material in this article are included in the article's Creative Commons licence, unless indicated otherwise in a credit line to the material. If material is not included in the article's Creative Commons licence and your intended use is not permitted by statutory regulation or exceeds the permitted use, you will need to obtain permission directly from the copyright holder. To view a copy of this licence, visit http://creativecommons.org/licenses/by/4.0/.

\section{References}

1. Chintapatla S, Safarani N, Kumar S, Haboubi N (2003) Sacrococcygeal pilonidal sinus: historical review, pathological insight and surgical options. Tech Coloproctol 7:3-8

2. de Parades V, de Parades V, Bouchard D et al (2013) Pilonidal sinus disease. J Visc Surg 150:237-247

3. Harries RL, Alqallaf A, Torkington J, Harding KG (2019) Management of sacrococcygeal pilonidal sinus disease. Int Wound $\mathrm{J}$ 16:370-378

4. Brown SR, Lund JN (2019) The evidence base for pilonidal sinus surgery is the pits. Tech Coloproctol 23:1173-1175

5. Burnett D, Smith SR, Young CJ (2018) The surgical management of pilonidal disease is uncertain because of high recurrence rates. Cureus 10:e2625

6. McCaughan D, Sheard L, Cullum N et al (2020) Nurse's and surgeon's views and experiences of surgical wounds healing by secondary intention: a qualitative study. J Clin Nurs 29:2557-2571

7. Brennan LK, Brownson RC, Orleans CT (2014) Childhood obesity policy research and practice: evidence for policy and environmental strategies. Am J Prev Med 46:e1-16

8. Cooper ID, Diane Cooper I (2016) What is a “mapping study?” J Med Library Assoc 104:76-78

9. Miake-Lye IM, Hempel S, Shanman R, Shekelle PG (2016) What is an evidence map? A systematic review of published evidence maps and their definitions, methods, and products. Syst Rev 5:28

10. Österberg M, Holmlund A, Sunzel B et al (2017) Knowledge gaps in oral and maxillofacial surgery: a systematic mapping. Int J Technol Assess Health Care 33:93-102

11. Behmanesh A, Sadoughi F, Mazhar FN et al (2020) Teleorthopaedics: a systematic mapping study. J Telemed Telecare 1357633 X20919308

12. Edwards P, Clarke M, DiGuiseppi C et al (2002) Identification of randomized controlled trials in systematic reviews: accuracy and reliability of screening records. Stat Med 21:1635-1640

13. Shemilt I, Khan N, Park S, Thomas J (2016) Use of cost-effectiveness analysis to compare the efficiency of study identification methods in systematic reviews. Syst Rev 5:140 
14. Mihala G, Grimwood K, Morley C et al (2020) Effect of definitions of acute gastroenteritis episodes using symptom diaries in paediatric cohorts: a systematic review. J Pediatr Gastroenterol Nutr 70:e54-e58

15. Harsløf T, Rolighed L, Rejnmark L (2019) Huge variations in definition and reported incidence of postsurgical hypoparathyroidism: a systematic review. Endocrine 64:176-183

16. Kraaijpoel N, Tritschler T, Guillo E et al (2019) Definitions, adjudication, and reporting of pulmonary embolism-related death in clinical studies: a systematic review. J Thromb Haemost 17:1590-1607

17. Nafiu OO, Tobias JD, DiNardo JA (2020) Definition of clinical outcomes in pediatric anesthesia research. Anesth Analg 130:550-554

18. Chapman SJ, Thorpe G, Vallance AE et al (2019) Systematic review of definitions and outcome measures for return of bowel function after gastrointestinal surgery. BJS Open 3:1-10

19. Mellor K, Hind D, Lee MJ (2018) A systematic review of outcomes reported in small bowel obstruction research. J Surg Res 229:41-50

20. Stubenrouch FE, Cohen ES, Bossuyt PMM et al (2020) Systematic review of reporting benefits and harms of surgical interventions in randomized clinical trials. BJS Open 4:171-181

21. Moonesinghe SR, Jackson AIR, Boney O et al (2019) Systematic review and consensus definitions for the Standardised Endpoints in Perioperative Medicine initiative: patient-centred outcomes. $\mathrm{Br}$ J Anaesth 123:664-670

22. Sahnan K, Tozer PJ, Adegbola SO et al (2019) Developing a core outcome set for fistulising perianal Crohn's disease. Gut 68:226-238

23. Page MJ, McKenzie JE, Kirkham J, et al (2014) Bias due to selective inclusion and reporting of outcomes and analyses in systematic reviews of randomised trials of healthcare interventions. Cochrane Database Syst Rev MR000035

24. Ergina PL, Barkun JS, McCulloch P et al (2013) IDEAL framework for surgical innovation 2: observational studies in the exploration and assessment stages. BMJ 346:f3011

25. Vohra RS, Spreadborough P, Johnstone M et al (2015) Protocol for a multicentre, prospective, population-based cohort study of variation in practice of cholecystectomy and surgical outcomes (The CholeS study). BMJ Open 5:e006399

26. Lee MJ, Sayers AE, Drake TM, et al (2019) National prospective cohort study of the burden of acute small bowel obstruction. BJS Open

27. Glancz LJ, Poon MTC, Coulter IC et al (2019) Does drain position and duration influence outcomes in patients undergoing Burr-Hole evacuation of chronic subdural hematoma? Lessons from a UK Multicenter prospective Cohort Study. Neurosurgery 85:486-493

28. Beal E, Hind D, Bradburn $M$ et al (2018) \#20 Design and rationale of the PIlonidal sinus Treatment - STudying the OPtions (PITSTOP) study: a multicentre cohort, nested mixed-methods case study and discrete choice experiment (poster presentation). Int J Surg 59:S6

29. Stewart AM, Baker JD, Elliott D (2011) The effects of a sacrococcygeal pilonidal sinus wound on activities of living: thematic analysis of participant interviews. J Clin Nurs 20:3174-3182

30. Stewart AM, Baker JD, Elliott D (2012) The psychological wellbeing of patients following excision of a pilonidal sinus. J Wound Care 21(595-6):598-600

31. McCaughan D, Sheard L, Cullum N et al (2018) Patient's perceptions and experiences of living with a surgical wound healing by secondary intention: a qualitative study. Int J Nurs Stud 77:29-38

32. Elwyn G, Barr PJ, Grande SW et al (2013) Developing CollaboRATE: a fast and frugal patient-reported measure of shared decision making in clinical encounters. Patient Educ Couns 93:102-107
33. Brehaut JC, O'Connor AM, Wood TJ et al (2003) Validation of a decision regret scale. Med Decis Making 23:281-292

34. Sahebally SM, McMahon G, Walsh SR, Burke JP (2019) Classical Limberg versus classical Karydakis flaps for pilonidal diseasean updated systematic review and meta-analysis of randomized controlled trials. Surgeon 17:300-308

35. Gavriilidis P, Bota E (2019) Limberg flap versus Karydakis flap for treating pilonidal sinus disease: a systematic review and metaanalysis. Can J Surg 62:131-138

36. Enriquez-Navascues JM, Emparanza JI, Alkorta M, Placer C (2014) Meta-analysis of randomized controlled trials comparing different techniques with primary closure for chronic pilonidal sinus. Tech Coloproctol 18:863-872

37. Horwood J, Hanratty D, Chandran P, Billings P (2012) Primary closure or rhomboid excision and Limberg flap for the management of primary sacrococcygeal pilonidal disease? A meta-analysis of randomized controlled trials. Colorectal Dis 14:143-151

38. Bi S, Sun K, Chen S, Gu J (2020) Surgical procedures in the pilonidal sinus disease: a systematic review and network metaanalysis. Sci Rep 10:13720

39. Milone M, Velotti N, Manigrasso M et al (2018) Long-term follow-up for pilonidal sinus surgery: a review of literature with metanalysis. Surgeon 16:315-320

40. Tien T, Athem R, Arulampalam T (2018) Outcomes of endoscopic pilonidal sinus treatment (EPSiT): a systematic review. Tech Coloproctol 22:325-331

41. Emile SH, Elfeki H, Shalaby M et al (2018) Endoscopic pilonidal sinus treatment: a systematic review and meta-analysis. Surg Endosc 32:3754-3762

42. Grabowski J, Oyetunji TA, Goldin AB et al (2019) The management of pilonidal disease: a systematic review. J Pediatr Surg 54:2210-2221

43. Hardy EJO, Herrod PJ, Doleman B et al (2019) Surgical interventions for the treatment of sacrococcygeal pilonidal sinus disease in children: a systematic review and meta-analysis. J Pediatr Surg 54:2222-2233

44. Berthier C, Bérard E, Meresse T et al (2019) A comparison of flap reconstruction vs the laying open technique or excision and direct suture for pilonidal sinus disease: a meta-analysis of randomised studies. Int Wound J 16:1119-1135

45. Cai LZ, Chang J, Weiser TG, Forrester JD (2017) Surgical site infections after tissue flaps performed in low- and middle-human development index countries: a systematic review. Surg Infect 18:765-773

46. Nguyen AL, Pronk AA, Furnée EJB et al (2016) Local administration of gentamicin collagen sponge in surgical excision of sacrococcygeal pilonidal sinus disease: a systematic review and meta-analysis of the literature. Tech Coloproctol 20:91-100

47. Halleran DR, Onwuka AJ, Lawrence AE et al (2018) Laser hair depilation in the treatment of Pilonidal disease: a systematic review. Surg Infect 19:566-572

48. Pronk AA, Eppink L, Smakman N, Furnee EJB (2018) The effect of hair removal after surgery for sacrococcygeal pilonidal sinus disease: a systematic review of the literature. Tech Coloproctol 22:7-14

49. Mostafaei S, Norooznezhad F, Mohammadi S, Norooznezhad AH (2017) Effectiveness of platelet-rich plasma therapy in wound healing of pilonidal sinus surgery: a comprehensive systematic review and meta-analysis. Wound Repair Regen 25:1002-1007

50. Mavros MN, Mitsikostas PK, Alexiou VG et al (2013) Antimicrobials as an adjunct to pilonidal disease surgery: a systematic review of the literature. Eur J Clin Microbiol Infect Dis $32: 851-858$

Publisher's Note Springer Nature remains neutral with regard to jurisdictional claims in published maps and institutional affiliations. 